\title{
A imagem de Julieta nos desenhos de Alexandra Exter
}

\author{
PRISCYLA KELLY VIEIRA ABREU
}

Priscyla Kelly Vieira Abreu é graduada em Design de Moda pela Universidade FUMEC, Belo Horizonte MG (2012), tem especialização em Moda, Cultura de Moda e Arte pela Universidade Federal de Juiz de Fora (2014) e mestrado em Artes pelo Programa de Pós-graduação em Artes da Universidade Federal de Uberlândia (2017), sob orientação de Alexander Gaiotto Miyoshi. Desenvolve pesquisas que abarcam a relação entre o vestuário e as artes no início do século XX, mulheres artistas e questões de gênero nas artes visuais. Bolsista CAPES, fez estágio de docência na disciplina Introdução à Crítica de Arte, na graduação em Artes Visuais da Universidade Federal de Uberlândia. 


\section{- RESUMO}

Neste artigo abordaremos os figurinos de Alexandra Exter para a peça Romeu e Julieta, dirigida por Alexander Tairov, em 1921. O objetivo é mostrar que os trajes criados por Exter, apesar do uso inovador de cores e formas geométricas, revelam a sobrevivência de características conservadoras em sua modelagem. Além disso, apontaremos a reincidência de outros elementos visuais que fazem alusão ao amor em perdição, como as espirais e as formas em redemoinho, a sugerir a antecipação ao desenlace trágico da história. Embora os desenhos de Exter tenham a função de atender a demanda para figurinos de teatro, nossa proposta é apresentar análises comparativas de imagens com abordagem temática semelhante, principalmente de personagens femininos.

\section{PALAVRAS-CAVE}

Arte, Figurino, Vanguarda.

\section{ABSTRACT}

This paper discusses the costume designs by Alexandra Exter for the play Romeo and Juliet, directed by Alexander Tairov in 1921. The aim is to show that the costumes created by Exter, despite the innovative use of color and geometric shapes, reveal the survival of conservative features in its modeling. In addition, we will point out the recurrence of other visual elements that allude to love in perdition, as spirals and forms swirling, suggesting the anticipation of the tragic end of the story. While Exter designs have the function to meet the demand for theater costume designs, our proposal is to present comparative analysis of images with similar thematic approach, especially female characters.

\section{KEYWORDS}

Art, Costume design, Avant-garde.

Romeu e Julieta, de William Shakespeare, conta a trágica história de amor de um jovem casal. Em Verona, Romeu e Julieta se conheceram no baile de máscaras, onde apaixonaram-se imediatamente. Porém, havia grande inimizade entre suas famílias, Montecchio e Capuleto, que se tornou ainda mais acirrada pela morte de Mercútio durante um duelo com Romeu. Apesar disso, a rivalidade não impediu o amor, e com a ajuda do Frei, Julieta forja sua própria morte para casar-se com Romeu. O Frei, contudo, não conseguiu informar Romeu sobre o plano, e este, ao encontrar Julieta desacordada, ingeriu todo o veneno para ficar ao lado de sua amada pela eternidade. Julieta desperta e vê o corpo de Romeu sem vida. Tomada por tristeza, apunhala-se e morre ao lado de seu grande amor. Como Romeu e Julieta, outras histórias de amor fadado à morte, como Francesca e Paolo, Tristão e Isolda, bem como histórias precedentes como Ippolito e Leonora, reforçam a voga aos mitos românticos profusamente retratados por artistas no século XIX. 
Os personagens de Shakespeare tornaram-se um tema recorrente nas artes. Em Romeu e Julieta, a cena do balcão (ato II), bem como o momento da morte (ato V), são os mais representados. Após o primeiro encontro do casal no baile de máscaras, Romeu reencontra Julieta no jardim dos Capuleto, onde declaram-se apaixonados. Desta cena (cena II, ato II) desdobraram-se diversas representações artísticas, tanto do encontro do casal quanto de Julieta sozinha. A pintura que William Powell Frith (figura 1) fez da personagem principal pode ser descrita através das palavras de Romeu ao avistar Julieta no balcão:

Que luz se escoa agora da janela? Será Julieta o sol daquele oriente?

Surge, formoso sol, e mata a lua cheia de inveja, que se mostra pálida

e doente de tristeza, por ter te visto que, como serva, és mais formosa que ela.

[...] Vê-de como ela apoia o rosto à mão. Ah! Se eu fosse uma luva dessa mão,

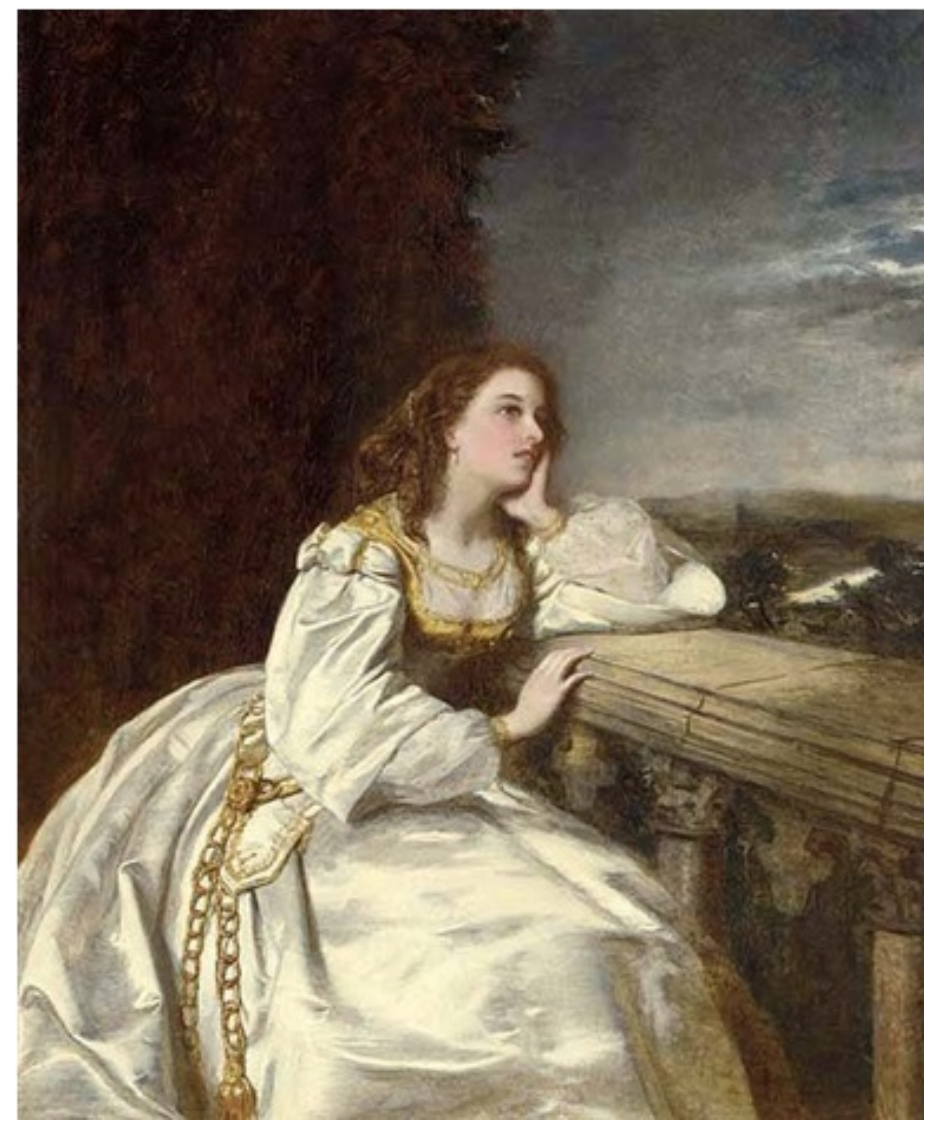

Figura 1. William Powell Frith, Julieta, 1862, óleo sobre tela, coleção privada. Fonte: Website Artnet. 
Alexandra Exter também representou Julieta e diversos personagens da peça. Como aponta HUNT (2011), em comparação com suas produções anteriores, como Famira Kifared (figura 2), em Romeu e Julieta Exter "esconde" (ou ressalta menos) os contornos, as formas do corpo humano por meio do volume dos trajes (figura 3). Também modifica a relação do figurino com o cenário através de efeitos tridimensionais. As cores dos figurinos, cenário e iluminação possibilitavam um movimento dinâmico no espaço cenográfico. Nesta produção, o trabalho cenográfico de Exter foi marcado por uma inovadora verticalidade e jogo de luz. ${ }^{1} \mathrm{O}$ espaço cênico era composto por sete praticáveis ligados por escadas. Elementos em metal e espelhos foram aplicados às armações do palco e ao vestuário, a refletir a luz e produzir efeitos contínuos de nuances de cor $^{2}$. Além disso, o desempenho dos atores em uma articulação rítmica assegurou as características dinâmicas à produção de Tairov.
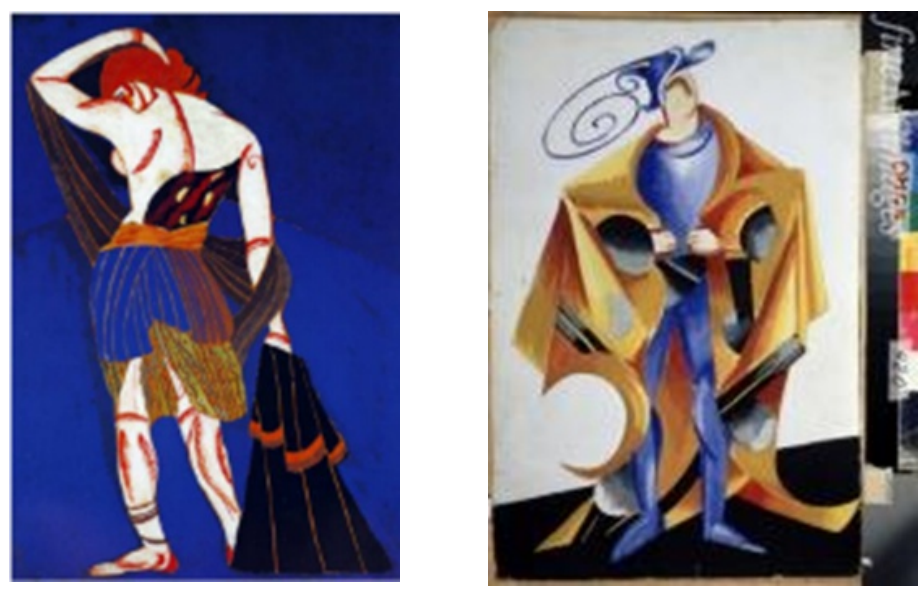

Figura 2. Alexandra Exter, Figurino para Famira Kifared, 1916. Fonte: STRIZHENOVA, 1991.

Figura 3. Alexandra Exter, figurino para Romeu e Julieta, 1921, guache sobre papel, Museu Regional de Arte M. Vrubel. Fonte: Website Fine Arts Images.

Nos figurinos femininos, Exter mesclou a modelagem do vestuário romântico-vitoriano e as características cubo-futuristas. As formas geométricas coloridas e sobrepostas compõem o traje das personagens, principalmente no volume da saia. As linhas retas são quebradas pelo volume arredondado das mangas bufantes e pela forma curvilínea que o traje atribui ao corpo. Em comparação com representações visuais que revelam a indumentária do final do século XIX e primeira década do século XX, como os conhecidos cartazes publicitários da Coca Cola (figuras $4 \mathrm{e}$ 5) e do pioneiro cartazista francês Jules Chéret (figura 6), observa-se que a maioria dos figurinos de Exter para personagens femininos corresponde à modelagem dos trajes tradicionais: o chapéu com penas posicionado na lateral da cabeça e as mangas e saias volumosas, a ressaltar a cintura exageradamente afinada. Até mesmo a pose das personagens de Exter apresentam semelhanças com as ilustrações publicitárias do século XIX, que além de sugerir a gestualidade do ator em cena, ressalta as formas do traje.

\footnotetext{
${ }^{1}$ Ver HUNT, 2011, p. 49.
}

2 Ver GUINSBURG, 2001. 

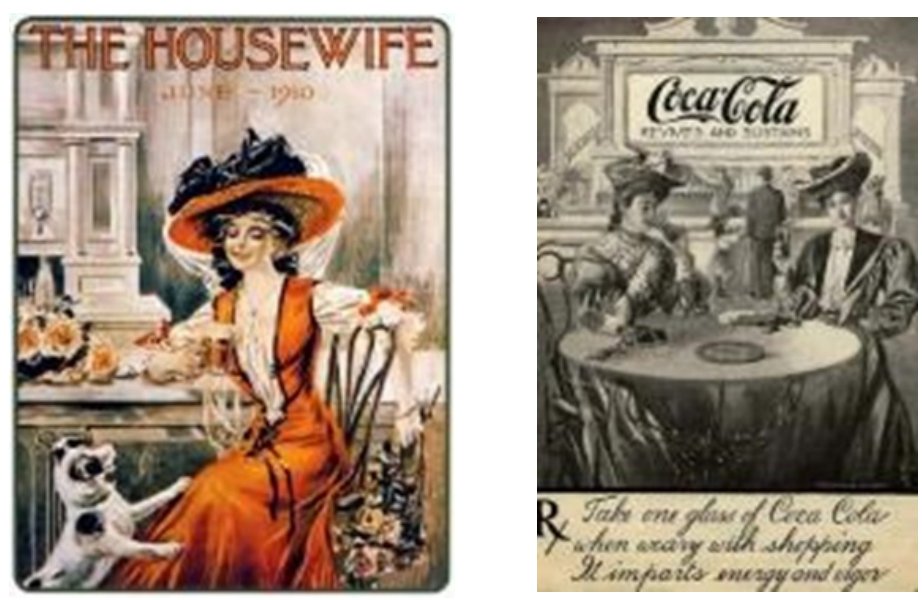

Figura 4. Cartaz publicitário, 1910. Fonte: Website Publistorm.

Figura 5. Cartaz publicitário da Coca Cola, 1896. Fonte: Website Propagandas Históricas.

Curiosamente, na construção destes figurinos (figuras 7 e 8), a artista faz referência a um período em que o vestuário enfatizava a fragilidade feminina e a diferenciação de gênero ${ }^{3}$ : o corpo enrijecido pelo espartilho a afinar a cintura forçadamente e a saia volumosa que restringe os movimentos do corpo. O tradicionalismo dos trajes, porém, é atenuado pelo toque de vanguarda de Exter, as cores enérgicas e a geometria das formas que o compõe.

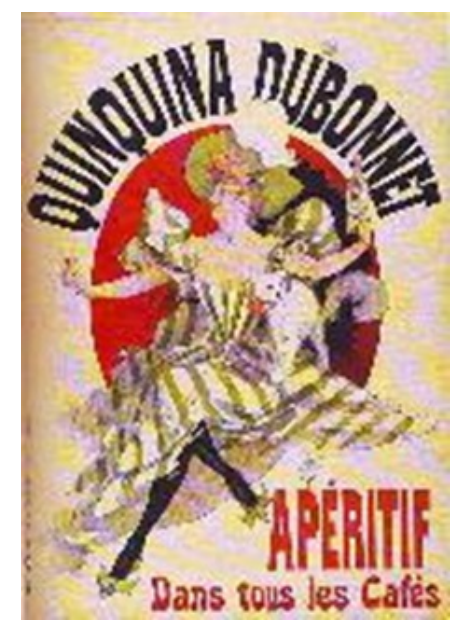

Figura 6. Jules Chéret, cartaz publicitário, 1895. Fonte: Website www.gallica.bnf.fr

\footnotetext{
${ }^{3}$ Sobre a questão da roupa como elemento que circunda a submissão feminina no século XIX, destaca-se o trabalho de XIMENES, 2011. 

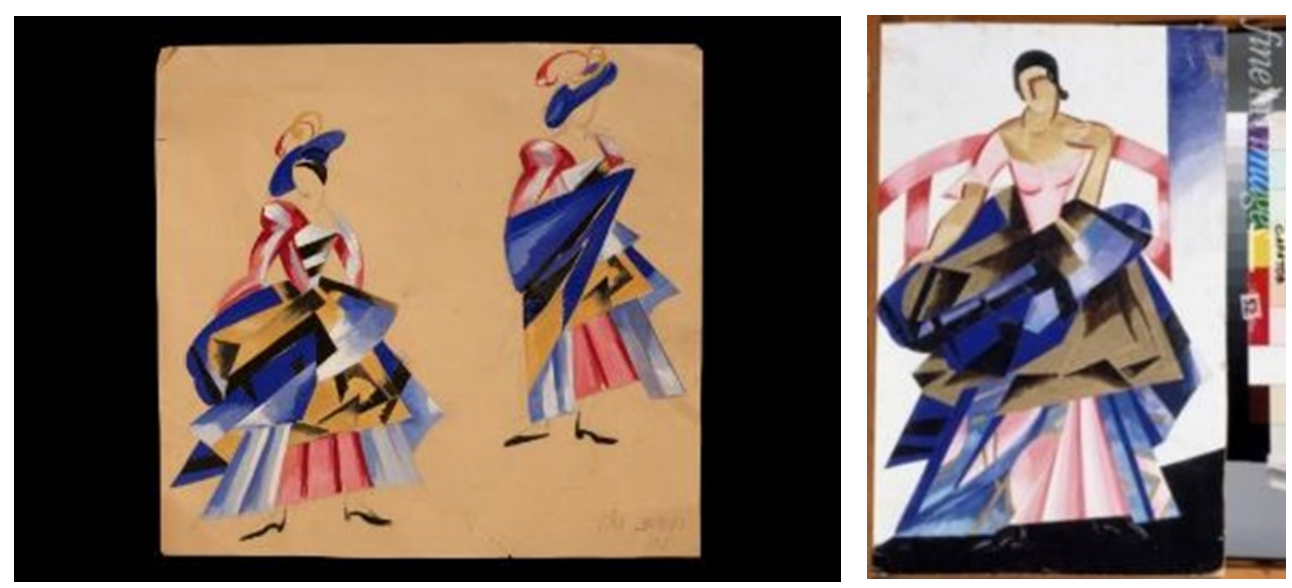

Figura 7. Alexandra Exter, figurino para Romeu e Julieta, 1920. Fonte: Wikimedia Commons Images.

Figura 8. Alexandra Exter, figurino para Romeu e Julieta, 1920. Fonte: Commons Wikimedia.

Para Julieta, Exter desenhou um figurino distinto das demais representações (figura 9). A pose da personagem sugere o movimento de dança e, ao contrário de outros figurinos femininos projetados pela artista, a saia do vestido de Julieta é curta e as mangas são ajustadas aos braços, a mostrar as pernas e os ombros. Vale mencionar que, de acordo com o andamento da pesquisa até o momento, este foi o único desenho de Exter criado especificamente para a personagem principal. Nem todas as fontes dos projetos de Exter apontam para qual personagem o figurino foi direcionado, o que indica a possibilidade de outros trajes mais tradicionais também terem sido elaborados para Julieta.

A Julieta de Exter distingue-se de outras representações da personagem, principalmente pelo desnudamento de partes do corpo e o uso de cores vibrantes. Comumente Julieta é representada com as vestes brancas, como podemos observar na obra do pintor inglês Thomas Francis Dicksee (figura 10), de 1875. Os projetos de Exter e a Julieta sobre o balcão, de Dicksee, compartilham semelhanças na modelagem do traje, como o corpete ajustado e o volume da saia. Contudo, as cores e formas que configuram a proposta de Exter para a construção de uma Julieta de vanguarda contrastam com a figuração de Dicksee. O contraste fica ainda mais evidente se compararmos com outra pintura, de Frank Bernard Dicksee - Romeu e Julieta, de 1884 (figura 11) - na qual o traje Julieta é branco, solto e fluido, aparentemente uma peça do vestuário íntimo. 


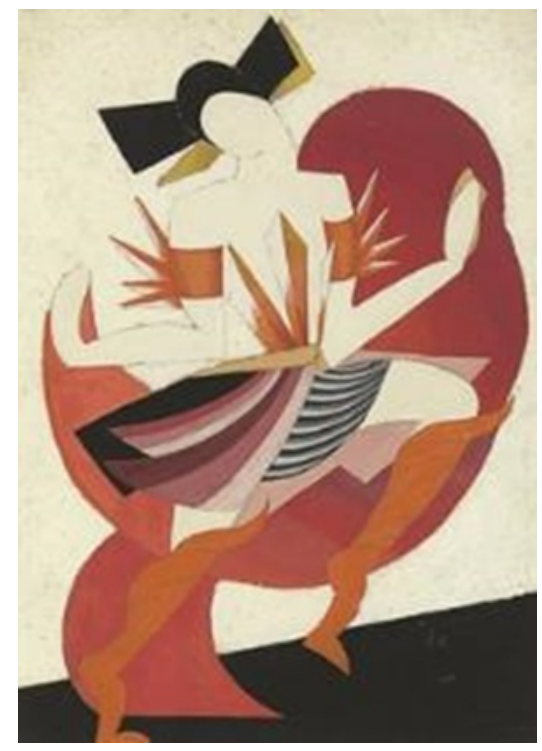

Figura 9. Alexandra Exter, Figurino para Romeu e Julieta: Julieta, 1920, guache sobre papel, $47.9 \times 34.3 \mathrm{~cm}$. Fonte: Website Christies.
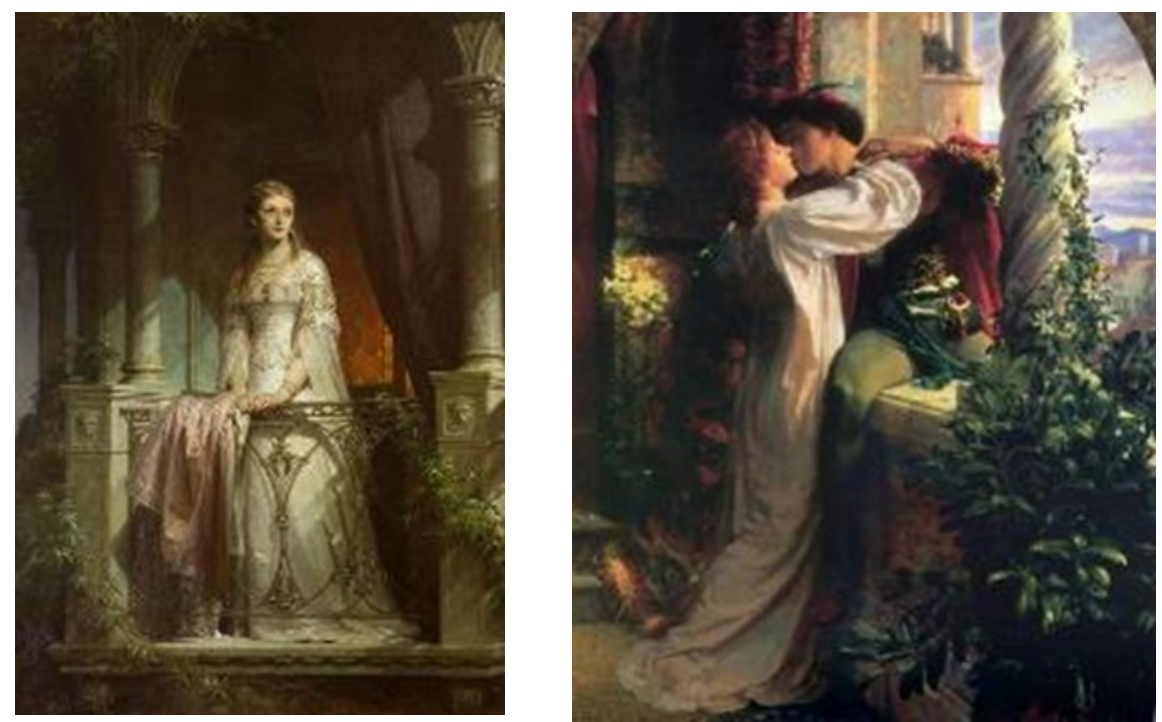

Figura 10. Thomas Francis Dicksee, Julieta sobre o balcão, 1875, óleo sobre tela. Fonte: Wikimedia Commons.

Figura 11. Frank Dicksee, Romeu e Julieta, 1884. Fonte: Wikimedia Commons. 
Na escultura, Pio Fedi representou os amantes que precederam a história de Romeu e Julieta. Leonora de Bardi e Ippolito Bondelmonte pertenciam a famílias rivais, por isso marcaram um encontro às escondidas com a ajuda da tia de Leonora. Ippolito, porém, foi preso no caminho sob a acusação de invasão à propriedade e intenção de roubo. Apesar de ter sido condenado, Ippolito confessa o roubo para proteger Leonora da culpa. Contudo, para não o perder, Leonora o salva da punição e anuncia publicamente o casamento, a reconciliar as duas famílias. Pesquisadores apontam o conto Istorietta amorosa fra Leonora de Bardi e Ippolito Bondelmonti como uma das fontes que inspiraram a história de Romeu e Julieta de Shakespeare 4 . Os amantes foram representados por Pio Fedi em uma extraordinária escultura (figura 12), distinta por detalhes minuciosos, principalmente no vestuário. O caimento do tecido na escultura de Pio Fedi é extremamente realista, bem como o relevo dos brocados e a textura das rendas. Como a Julieta de Frank Bernard Dicksee, o traje de Leonora aparenta leveza e movimento fluido, sem a rigidez da modelagem presente nas vestes de outras representações da personagem.
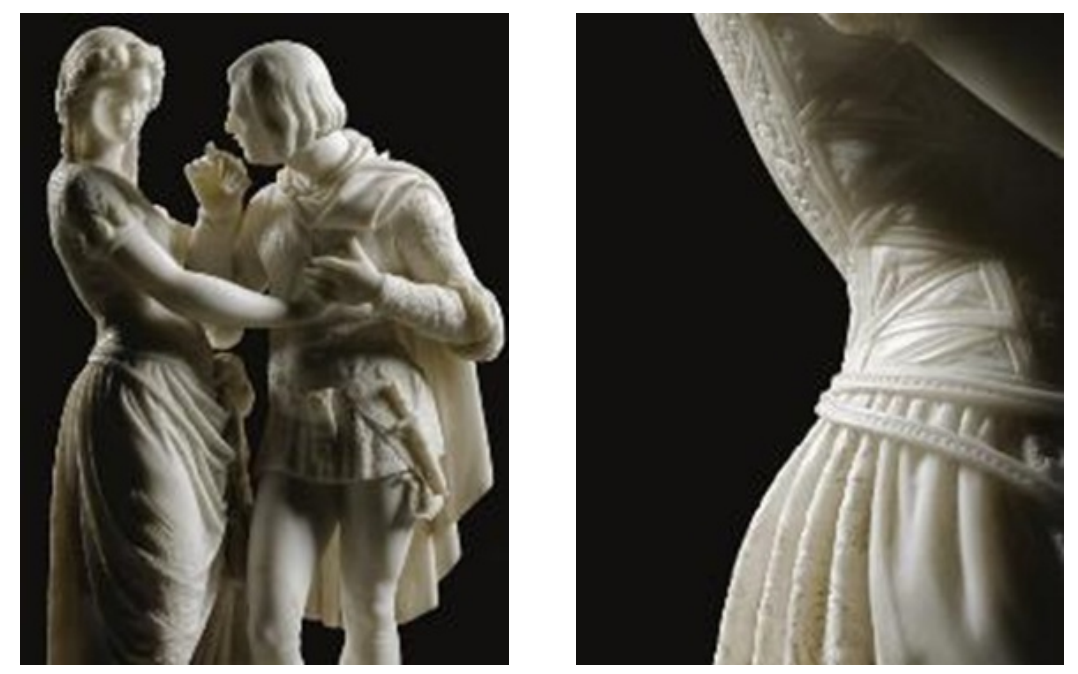

Figura 12. Pio Fedi, Leonora de Bardi e Ippolito Bondelmonte, 1872, mármore branco. Fonte: Website Tutt'Art.

Figura 13. Pio Fedi, detalhe da escultura Leonora de Bardi e Ippolito Bondelmonte, 1872, mármore branco.

Em 1911, Percy Macquoid desenhou figurinos para Julieta (figuras 14 e 15). Muito semelhantes à Leonora de Pio Fedi, os desenhos de Macquoid também apresentam tecidos mais fluidos na composição dos trajes. O movimento do corpo da Julieta de Macquoid é semelhante ao gesto delicado de Leonora e ambas apresentam a cabeça levemente inclinada, a apontar os olhos para baixo.

$\overline{{ }^{4} \text { Ver PRUNSTER, } 2000 .}$ 
As obras que fazem referência à tragédia de Shakespeare variam de acordo com o ato representado. Na pintura, comumente Julieta está ao lado de Romeu. Na obra de Eugène Delacroix (figura 16), por exemplo, Romeu apoia Julieta desacordada em seus braços, com o corpo envolto em lençóis brancos e os seios à mostra. Esta composição rememora outra história de amor trágico, de Francesca de Rimini e Paolo Malatesta, com representações artísticas análogas a Romeu e Julieta. Francesca, filha do governante de Ravena, foi concedida por seu pai a casar-se com Giovanni Malatesta, como um acordo de paz. Esta, porém, apaixonou-se pelo irmão mais novo, Paolo Malatesta, e logo tornaram-se amantes. O trágico fim do romance ocorreu quando o casal foi surpreendido por Giovanni e assassinado por ele. Gustave Doré representou diversos episódios do Inferno, de Dante Alighieri, entre eles o momento em que Dante e Virgílio encontram Paolo e Francesca (figura 17). Esta cena tornou-se uma das mais representadas nas artes, e aproxima-se da pintura de Delacroix, pois ambas as personagens - Julieta e Francesca - apresentam posturas quase idênticas, exceto pelo movimento dos braços.
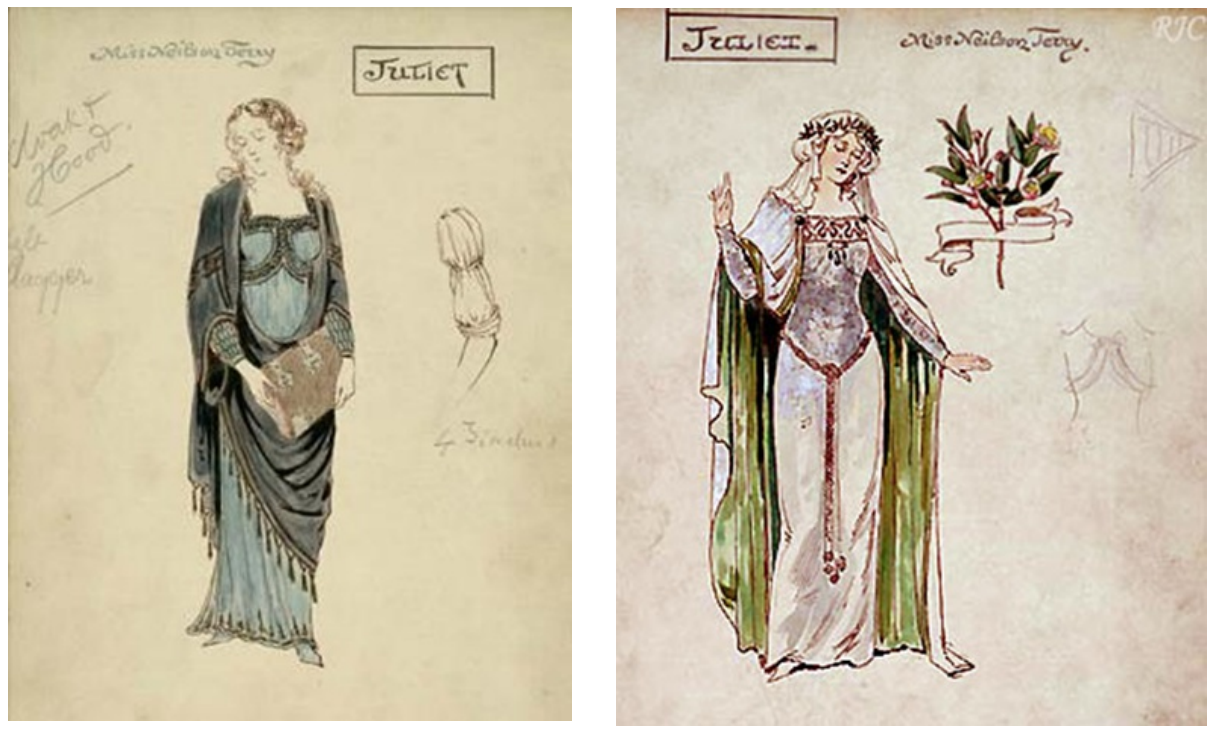

Figura 14. Percy Macquoid, desenho de figurino para Julieta, 1911.

Figura 15. Percy Macquoid, desenho de figurino para Julieta, 1911. 

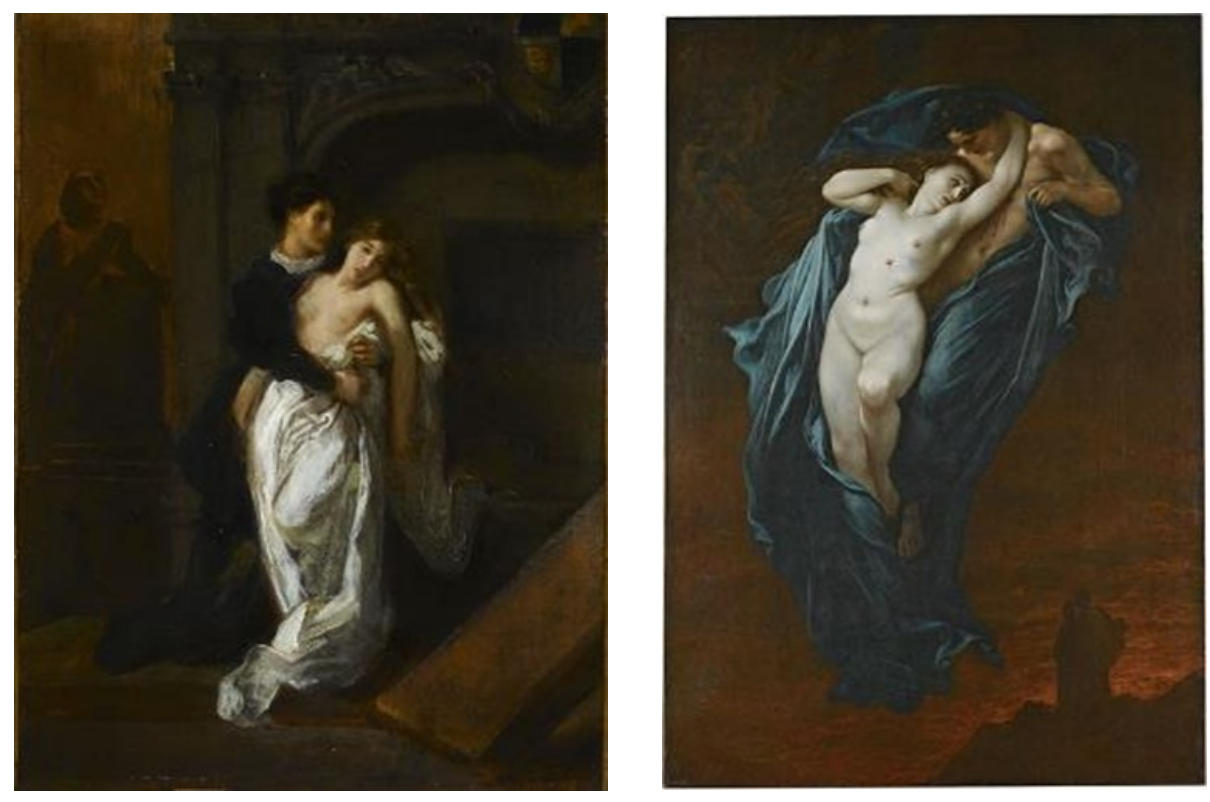

Figura 16. Eugène Delacroix, Romeu e Julieta, 1846. Fonte: Website Musée Delacroix.

Figura 17. Gustave Doré, Paolo e Francesca da Rimini, 1863, óleo sobre tela. Fonte: Wikimedia Commons.

A aproximação entre as representações dessas duas histórias se repete em outras obras, como nas pinturas de Ary Scheffer, e Lord Frederick Leighton, ambas do século XIX. Francesca da Rimini é uma das pinturas mais admiradas de Ary Scheffer (figura 18). Nesta, Dante e Virgílio observam os corpos dos amantes Paolo e Francesca a flutuar no segundo círculo do Inferno, condenados por luxúria. 0 gesto de Francesca envolvendo Paolo com os braços, a pendurar-se no ombro de seu amante, é semelhante ao de Romeu e Julieta na pintura de Lord Leighton, em A Reconciliação dos Montagues e Capuletos sobre os cadáveres de Romeu e Julieta (figura 19). Além disso, as duas figuras masculinas posicionadas ao lado dos cadáveres na obra de Lord Leighton remetem a disposição de Dante e Virgílio de Ary Scheffer, embora com gestos distintos. 

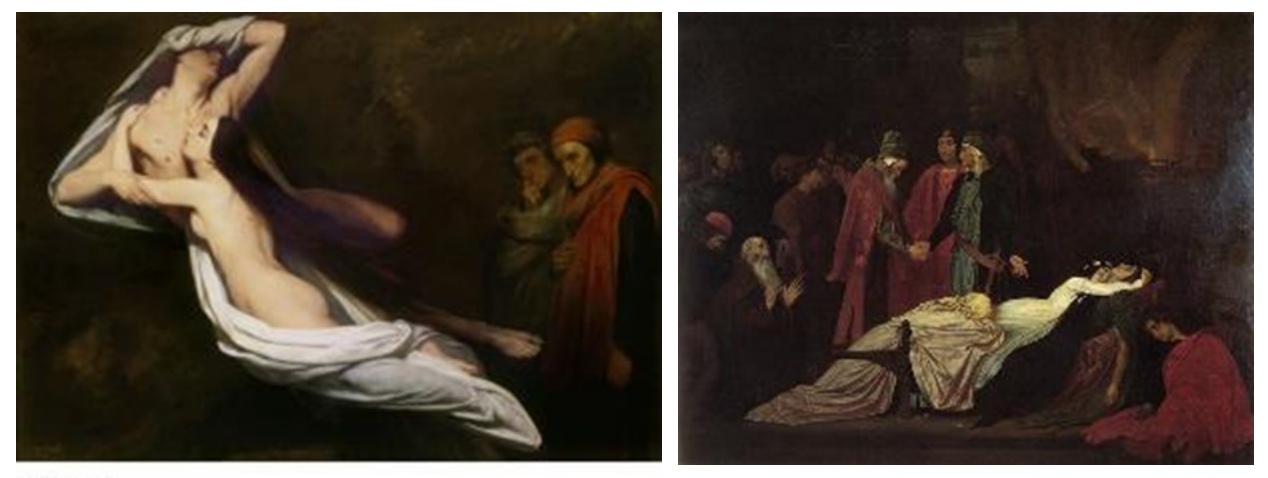

Figura 18. Ary Scheffer, Francesca da Rimini, 1854. Fonte: Website Wallace Collection.

Figura 19. Lord Frederick Leighton, A Reconciliação dos Montagues e Capuletos sobre os cadáveres de Romeu e Julieta, 1855, Fonte: Wikimedia Commons.

O conceito romantizado da invalidez como característica da "natureza" feminina foi bastante disseminado entre artistas e poetas do século XIX ${ }^{5}$. Para além do imaginário artístico, isso afetou a vida das mulheres por disseminar a ideia de que o vigor físico feminino era uma atitude perigosa e masculinizante. Com isso, a mulher saudável não era acatada como "natural". Nesse empreendimento, semeIhante à representação de Julieta em sono profundo (figura 20), Joseph Noël Paton pintou The Dead Lady (figura 21), que, segundo Bram Dijkstra, possui duas opções narrativas baseadas no conceito da relação masculino-feminino em meados do século XIX: por um lado pode-se tomar a posição masculina e o sentimentalismo sádico-agressivo do dominador por quem a mulher morreu, por outro lado o prazer passivo-masoquista de auto sacrifício, centralizado na figura da jovem morta.

Seguindo esta mesma linha, vale mencionar outro casal cuja história não deixa de corresponder à de Romeu e Julieta. A história de Tristão e Isolda é originária de uma lenda celta e se desdobrou em diversas versões. Tristão conhece Isolda em uma viagem a Irlanda, com o intuito de levá-la para casar-se com seu tio, rei Marcos. Acidentalmente, Tristão e Isolda bebem uma poção mágica do amor e apaixonam-se, mas são fadados a viverem separados devido ao casamento ao qual a princesa foi prometida. Após muitas aventuras, Tristão é ferido e, prestes a morrer, solicita a presença de Isolda para cura-lo. Isolda reencontra Tristão já morto, e de tristeza também dá o último suspiro sobre o corpo de seu amado. $O$ artista espanhol Rogelio de Egusquiza representou a morte do casal (figura 22). Nesta obra, o corpo de Isolda jaz sobre Tristão, ambos sem vida, e o fetiche pelo corpo falecido é reforçado pelas vestes de Isolda, o tecido que transparece o corpo e os seios nus.

\footnotetext{
$\overline{{ }^{5} \text { Ver DIJKSTRA, }} 1986$.
} 

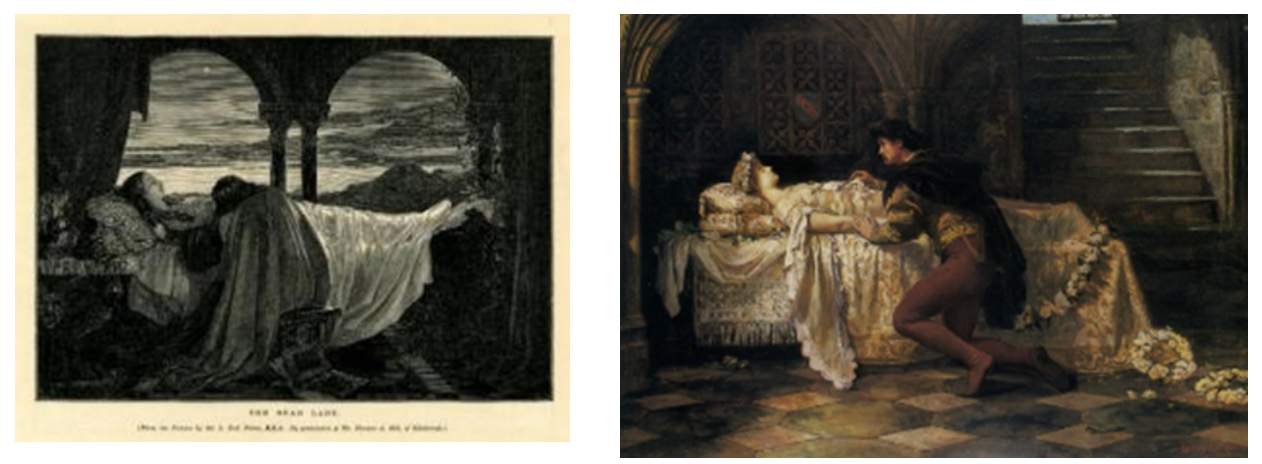

Figura 20. Joseph Noel Paton, The Dead Lady, 1854, Fonte: Website British Museum.

Figura 21. Sydney Muschamp, Romeu e Julieta, 1886, óleo sobre tela, fonte: Wikimedia Commons

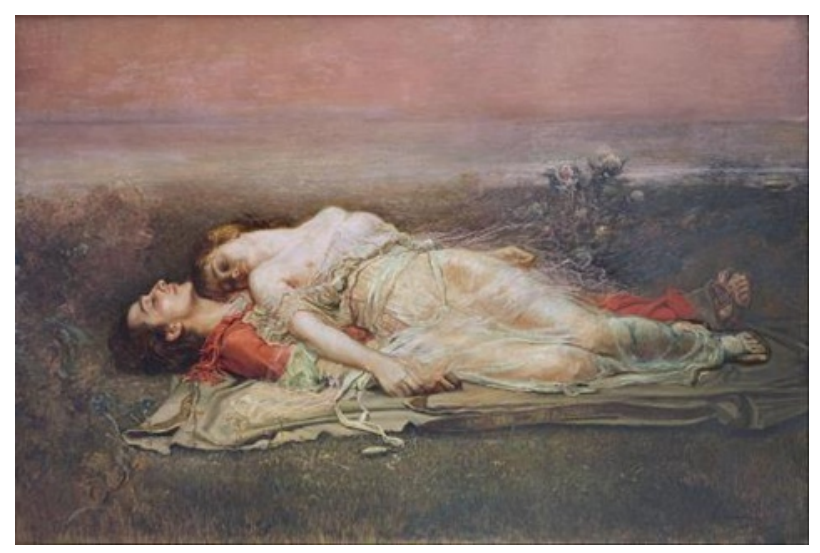

Figura 22. Rogelio de Egusquiza, Tristão e Isolda, 1910, óleo sobre tela, Museu de Belas Artes de Bilbal, fonte: Wikimedia Commons.

Devido ao caráter instrumental, os desenhos de Exter contrastam com as figurações mencionadas acima. Dentre as propostas da artista para a peça, nenhuma apresenta um vestuário que desvele o corpo das personagens, exceto os vestidos que possuem a saia mais curta. Ao contrário, as formas naturais do corpo, tanto feminino quanto masculino, quase desaparecem em meio a volumosa sobreposição de formas geométricas, que segundo Georgii Kovalenko ${ }^{6}$, compõem um estilo "Cubo-Baroque". Porém, em comparação com outras representações, observa-se no desenho de Exter a marcante sobrevivência da modelagem do vestuário comumente atribuído à personagem. Na obra do pintor francês Henri Pierre Picou (figura 23), do século XIX, Julieta exibe o suntuoso traje peculiar ao período do Romantismo. O tecido inflado na volumosa manga bufante e os seios fartos, apertados pelo corpete, rememoram a silhueta dos figurinos de Exter.

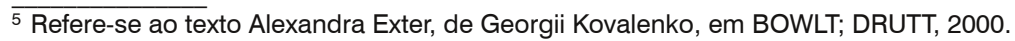




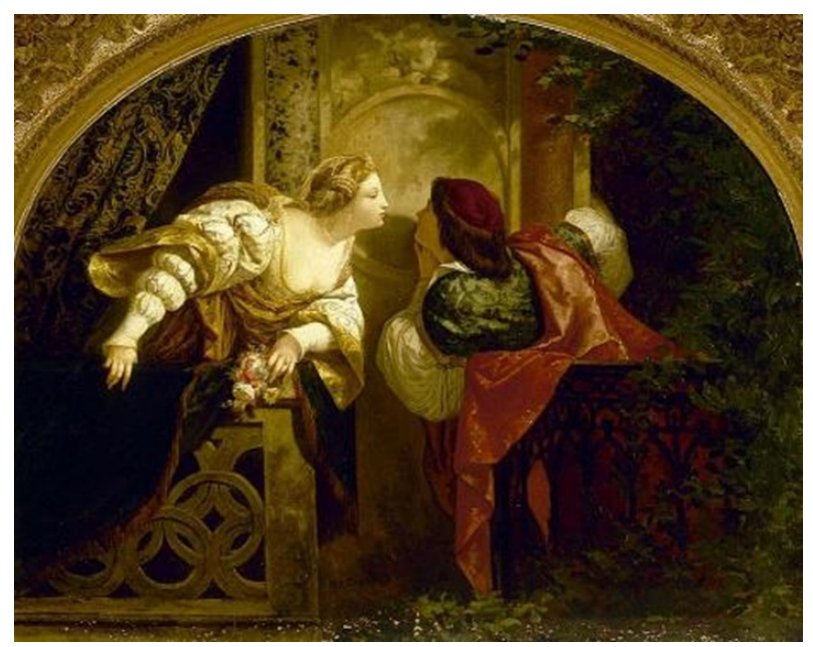

Figura 23. Henri Pierre Picou, Romeu e Julieta, sem data, 48 X $60 \mathrm{~cm}$, Fonte: Wikimedia Commons

Através da extraordinária afinidade de cores, uma das personagens femininas de Exter (figura 7) aproxima-se da Isolda representada por Frederick Sandis (figura 24). O azul é predominante no traje de ambas as personagens. Segundo a lenda, a roseira e a videira plantadas no local da morte de Tristão e Isolda se entrelaçaram com o passar do tempo, portanto a rosa vermelha - cor também presente na proposta de Exter - em uma das mãos de Isolda representa a eternidade do amor. O amarelo da tiara que enfeita os cabelos de Isolda e da taça com a poção mágica também aparecem em detalhes do figurino projetado por Exter. Apesar de pertencerem a culturas e tempos diferentes, ambas compartilham as mesmas tonalidades.

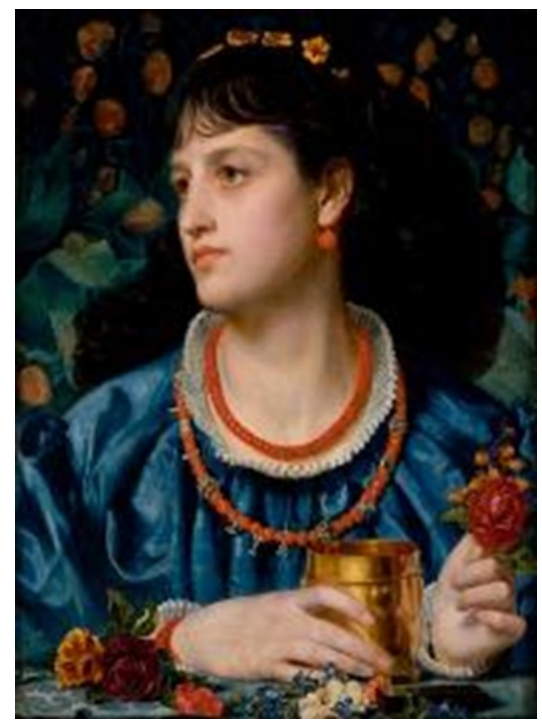

Figura 24. Frederick Sandis, Isolda com la Poción de Amor, 1870, óleo sobre madeira, Museu de Arte de Ponce. Fonte: Wikimedia Commons. 
Dentre os diversos projetos de Exter para os figurinos da peça, alguns apresentam linhas retas e formas angulares, outros são mais curvilíneos, sem reduzir, porém, o volume e aspecto enérgico do traje. Alguns desses desenhos recriam soluções formais de outros artistas, em representações de Romeu e Julieta. As formas circulares e o caimento do tecido nos desenhos de Exter lembram as do pintor Ford Madox Brown, de 1870 (figura 26). O tecido que recai no braço de um dos personagens de Exter (figura 25) rememora o movimento da manga do vestido da Julieta de Brown, e o tecido que se desenrola no braço esquerdo de Romeu tem movimento semelhante ao de outro figurino projetado por Exter (figura 27), sobretudo em contraponto a um elemento prismático horizontal: em Brown, braço e mão estendidos; em Exter, o chapéu em forma de cone. Além disso, o piso sobre o qual os personagens de Exter se apoiam e o balcão de Brown são oblíquos, a refletir na similaridade do movimento corporal de ambos os personagens.
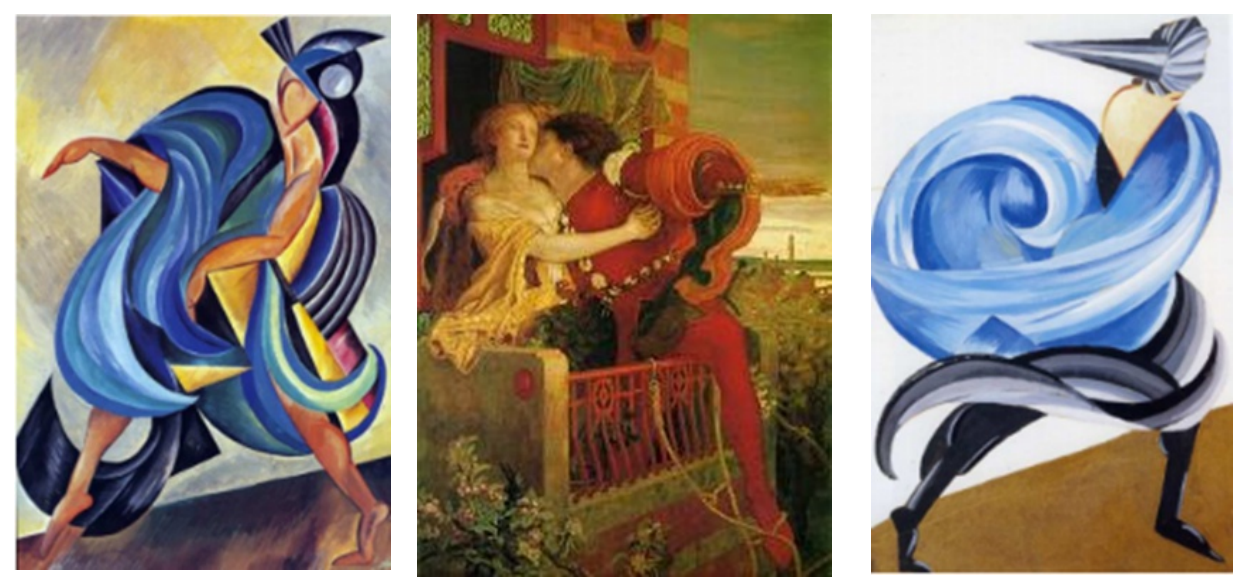

Figura 25. Alexandra Exter, Figurino para Romeu e Julieta, 1921. Fonte: HUNT (2011).

Figura 26. Ford Madox Brown, Romeu e Julieta, 1870, óleo sobre tela, Manchester Art Galery.

Figura 27. Alexandra Exter, Figurino para Romeu e Julieta, 1921. Fonte: HUNT (2011).

Os arabescos e as formas espirais se repetem no movimento rítmico dos traços de Exter para outros personagens da mesma peça (figura 28), até mesmo no detalhe dos calçados de Julieta (figura 29), a envolver suas pernas em um movimento helicoidal. Na pintura de Herbert James Draper (figura 30), o detalhe se repete no vestido de Isolda, que também possui espirais bordadas no busto. Seja para suavizar esteticamente os figurinos da tragédia ou para simbolizar o amor em perdição, estas formas espiraladas ressaltam ainda mais as reminiscências de outras representações com abordagem temática análoga. 

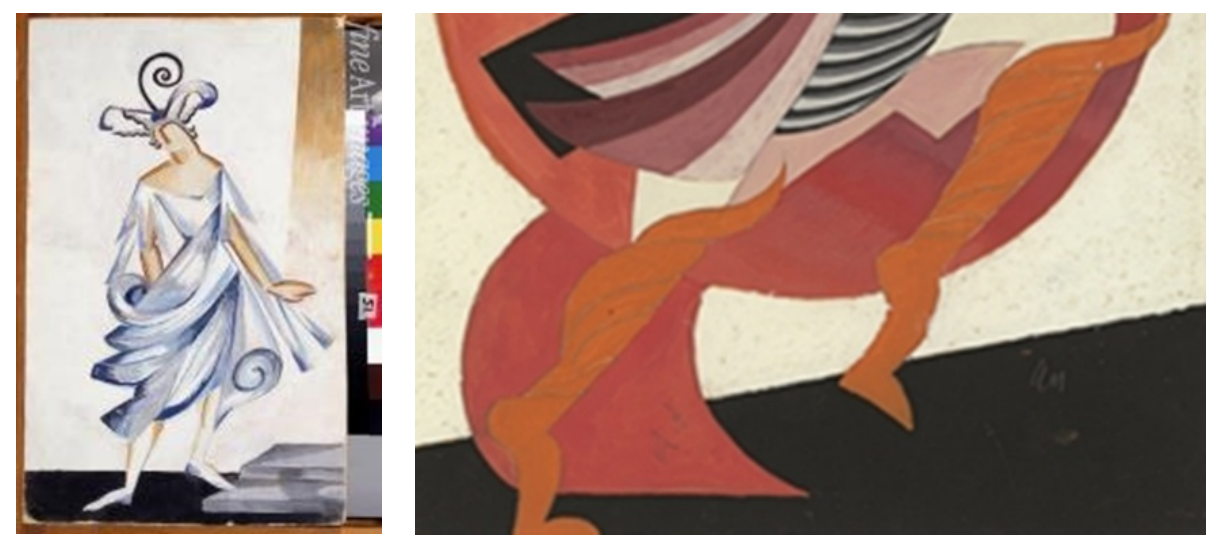

Figura 28. Alexandra Exter, Figurino para Romeu e Julieta, 1921, guache sobre papel. Fonte: Website Fine Art Images.

Figura 29. Alexandra Exter, Detalhe do figurino para Julieta, 1921. Fonte: Website Christies.

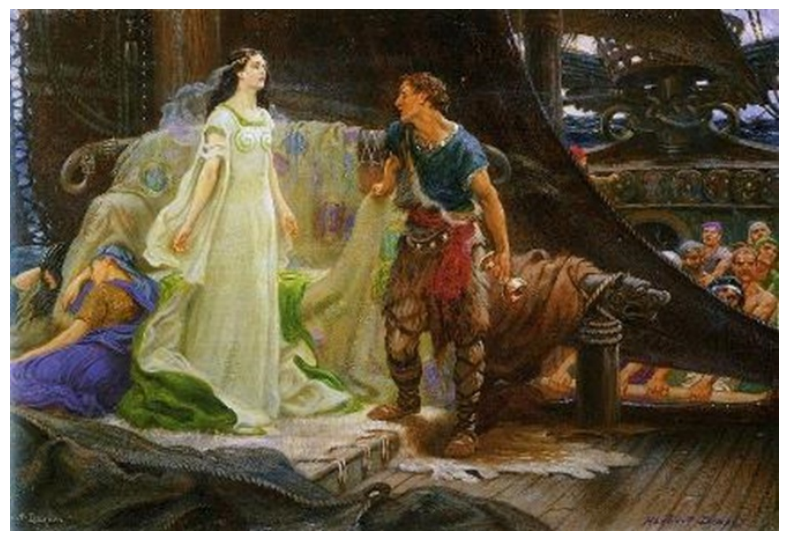

Figura 30. Herbert James Draper, recorte da obra Tristão e Isolda, 1901. Fonte: Wikimedia Commons.

Liubov Popova, artista contemporânea a Exter, também projetou figurinos para Romeu e Julieta. Paralelamente, as duas mulheres artistas elaboraram elementos visuais para a interpretação de Tairov da tragédia de Shakespeare. Os desenhos de Popova (figuras 31 e 32) ressaltam as características do Construtivismo em sua vestimenta, inclusive no que sugere ser o penteado nos cabelos. Ambas as representações de personagens femininas - a de Exter e Popova - possuem volume, formas dinâmicas e são constituídas por traços abstratos marcantes, que atenuam a suavidade em relação à outras representações de Julieta. Porém, o grau de abstração de Popova sugere que Exter preocupou-se em desenvolver desenhos 
mais técnicos para a confecção dos trajes, a reforçar ainda mais a sobrevivência da caracterização tradicional das personagens. Segundo Charlotte Douglas ${ }^{7}$, Tairov havia advertido as artistas contra o excesso de similaridade com as peças tradicionais, bem como sobre a liberdade para a inversão de gênero dos atores e personagens: "as mulheres podem substituir os homens, e vice-versa" (apud BOWLT, 2000, p. 52) (tradução nossa). Os desenhos de Exter para a peça, observa o autor, eram coloridos e exuberantes, enquanto os de Popova eram mais sóbrios. Certamente, estas questões somadas ao aspecto mais técnico da proposta de Exter contribuíram para que seus trabalhos fossem selecionados para a produção.
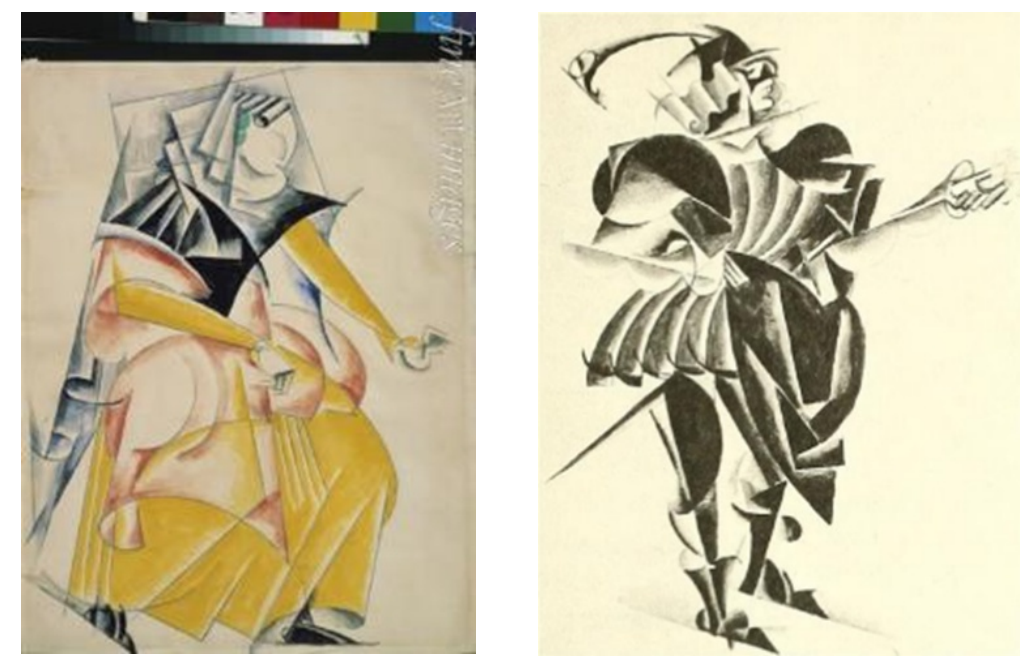

Figura 31. Liubov Popova, figurino para Romeu e Julieta, 1920. Fonte: Website Fine Art Images.

Figura 32. Liubov Popova, figurino para Romeu e Julieta, 1921. Fonte: BOWLT, 2000.

Apesar dos exuberantes trajes de Exter terem sido escolhidos para a peça, não agradou aos críticos daquela época. De acordo com Bowlt, a produção não teve sucesso devido ao "excesso decorativo", que nas palavras do autor "parecia mais adequado para uma pantomima ou circo" (BOWLT, 1977, p. 70) (tradução nossa). Ainda segundo Bowlt, a concepção de Exter foi considerada estranha e mencionada por alguns críticos como "a mais amarga página" (BOWLT, 1977, p. 70) (tradução nossa) da história do Chamber Theatre. Ainda sobre a peça, Guinsburg aponta:

\footnotetext{
${ }^{7}$ Refere-se ao texto de Charlotte Douglas, Six (and a few more) Russian Women of the Avant-Garde Together,
} em BOWLT; DRUTT, 2000. 
Ainda que os trabalhos cênicos ... tenham sido menos satisfatórios do que prometiam a leveza, o colorido, o equilíbrio entre retas e curvas, espirais e ângulos, entre massa 'construída' e linha dinamizada dos esboços feitos pela cenógrafa, pois ao serem materializados no palco os sólidos projetados converteram-se em estruturas pesadas, e ainda que retivessem, em contrapartida, talvez pela própria estilização e harmonia das combinações e dos efeitos pictóricos utilizados, um certo caráter de décor mais do que o de instalação cenográfica - ainda assim uma pesquisa na direção de um certo construtivismo com base no cubismo sintético se evidenciava. (GUINSBURG, 2001, p. 179)
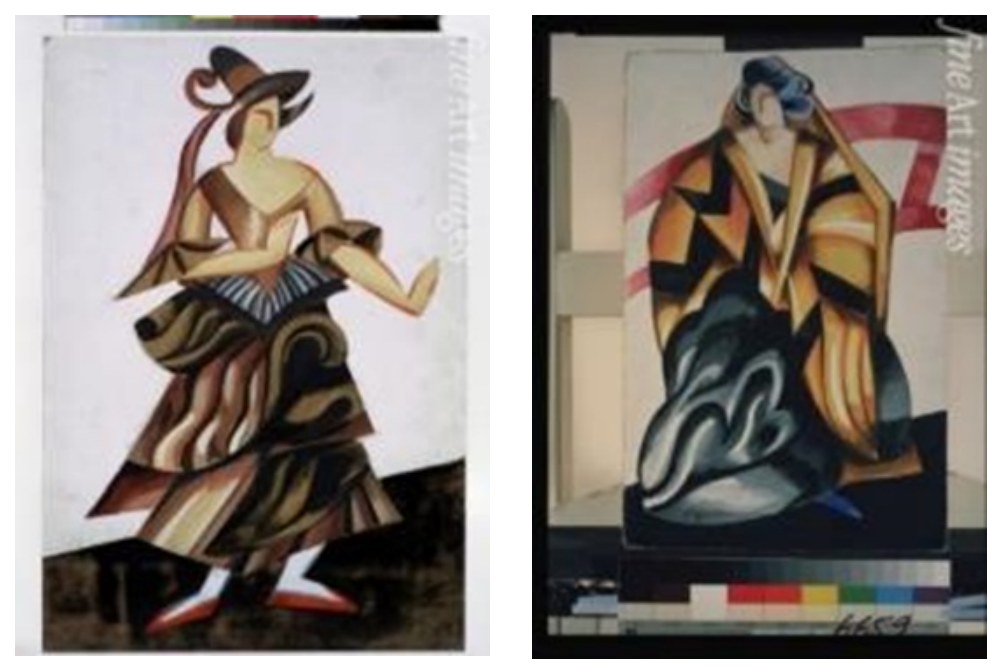

Figura 33. Alexandra Exter, Figurino para Romeu e Julieta, 1921, lápis e guache sobre cartão, State Tretyakov Gallery, Russia.

Figura 34. Alexandra Exter, Figurino para Romeu e Julieta - Ama de leite, 1921, guache sobre papel, State Tretyakov Gallery, Moscou. Fonte: Website Fine Arts.

Ao comparar os projetos de Exter com as demais representações de Romeu e Julieta, fica evidente a introdução de seu próprio estilo pictórico na composição dos figurinos. O conjunto de peças geométricas formam o caimento do tecido, anteriormente representado de maneira mais realista. Contudo, os desenhos de Exter contém elementos comumente representados na figura dos personagens: as máscaras, os chapéus e as formas dos vestidos aos moldes do século XIX. Nem mesmo os trajes masculinos escaparam ao tradicionalismo formal, com as calças ajustadas, as casacas e o acessório de cabeça com penas, como podemos observar no desenho de Exter para Gregorio (figura 36) em comparação com o traje de Romeo, na pintura de Francesco Hayez (figura 37). Estas características reforçam o quão marcante é a imagem que se construiu destes personagens. 


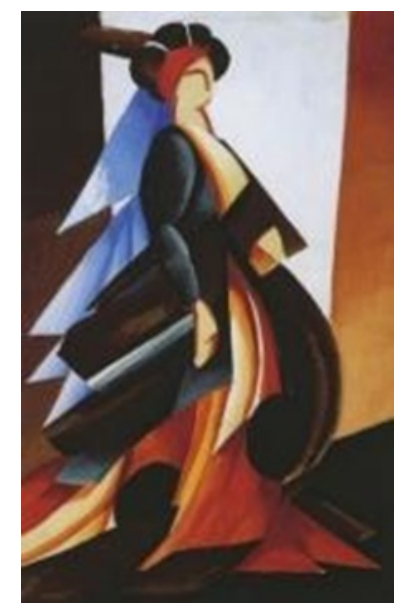

Figura 35. Alexandra Exter, Figurino para Romeu e Julieta - Lady Montecchio, 1921, guache sobre papel. Fonte: Website Art Archive.
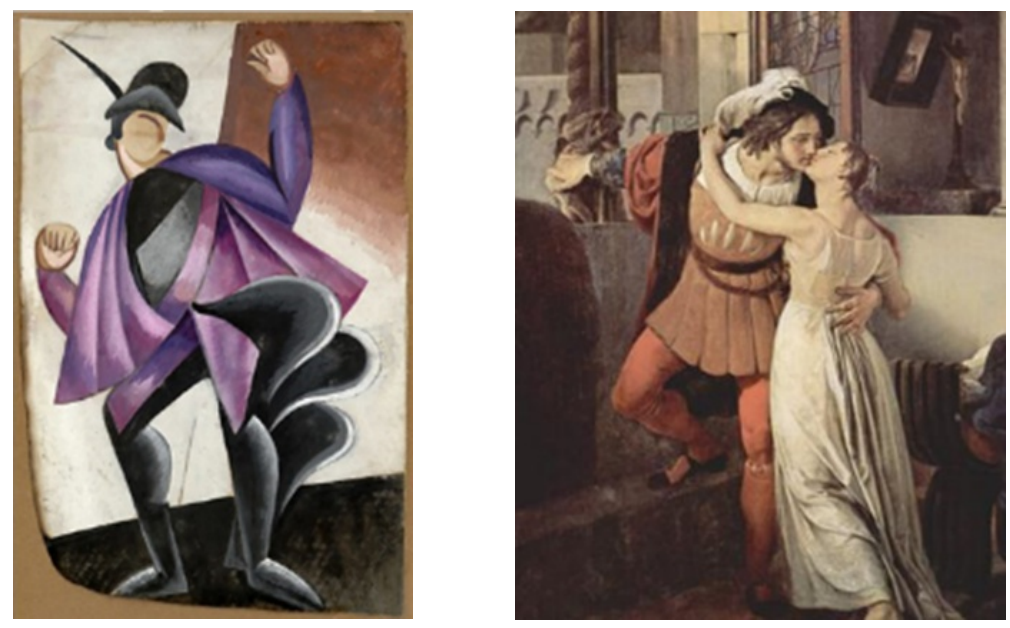

Figura 36. Alexandra Exter, Figurino para Gregório, de Romeu e Julieta, 1921. Fonte: Website bbc.co.uk.

Figura 37. Francesco Hayez, recorte da obra O último beijo de Romeu e Julieta, 1823, óleo sobre tela. Fonte: Wikimedia Commons.

Mesmo com tantos elementos tradicionais, os desenhos de Exter possuem caráter forte e marcante. As formas rítmicas e a vivacidade das cores da vestimenta conferem aos personagens certa agressividade. Por tratar-se de um desenho instrumental para a confecção do figurino, a Julieta de Exter, bem como as demais personagens femininas, não possui expressão facial, mas é destemida em sua pose, a afrontar com seu gesto dançante outras representações de Julietas lamuriosas ou em sono profundo. 


\section{Referências}

BOWLT, John E. Construtivism and Russian Stage Design. Performing Art Journal. Vol. 1, № 3, p. 62-84, 1977. <https://doi.org/10.2307/3245250>

COLI, Jorge. O corpo da liberdade: Reflexões sobre a pintura do século XIX. São Paulo: Cosac Naify, 2010 .

DIJKSTRA, Bram. Idols of Perversity: Fantasies of Feminine Evil in Fin-de-Siècle Culture. Nova York: Oxford University Press, 1986.

FIGUEIREDO, Maria do Anjo Braacamp (Tradução). Tristão e Isolda. Rio de Janeiro: F. Alves, 1997.

GINZBURG, Carlo. Medo, reverência, terror: quatro ensaios de iconografia política. São Paulo: Cia. das Letras, 2014.

GUINSBURG, J. Stanislávski, Meierhold \& Cia. São Paulo: Editora Perspectiva, 2001.

HUNT, Laura A. From Performer to Petrushka: A Decade of Alexandra Exter's Work in Theater and Film. Dissertação de mestrado. Atlanta: Georgia State University, 2011.

PRUNSTER, Nicole. Romeo and Juliet before Shakespeare. Victoria University (Toronto, Ont.). Centre for Reformation and Renaissance Studies, 2000.

SHAKESPEARE, William. Romeu e Julieta; Tito Andronico. Tradução de Carlos Alberto Nunes. São Paulo: Melhoramentos, 1998.

STRIZHENOVA, Tatiana Konstantinovna. Soviet Costume and Textiles: 1917-1945. Paris: Flammarion, 1991.

XIMENES, Maria Alice. Arte e moda na reinvenção do corpo feminino do século XIX. São Paulo: Estação das Letras e Cores, 2011.

WARBURG, Aby. A renovação da Antiguidade pagã: Contribuições científico-culturais para a história do Renascimento europeu. Rio de Janeiro: Contraponto / MAR, 2013.

WHITE, Christine A. Directors and Designers. Intellect Books, 2009.

Websites:

Association Alexandra Exter: <http://www.alexandra-exter.net/fr/>

Recebido em 11/08/2016 - Aprovado em 26/09/2017 